\title{
2D SERVO VALVE WITH A ZERO-OVERLAP OF PILOT STAGE
}

\author{
Sheng LI, Jian RUAN, Xiang PEI, Zheqing YU and Faming ZHU \\ The MOE Key Laboratory of Mechanical Manufacture and Automation \\ Zhejiang University of Technology \\ Hangzhou, 310014, China \\ (E-mail: li_sheng@mail.hz.zj.cn)
}

\begin{abstract}
A $2 \mathrm{D}$ servo valve designed with zero-overlap is proposed. First, the pilot leakage of the $2 \mathrm{D}$ servo valve with a zero-overlap of pilot stage is analyzed theoretically. Based on the analysis to the flow field of the clearance between two parallel plates, the overall pilot leakage is calculated through integration. Secondly, the mathematical model of the axial motion of the spool in respect to rotary motion is established and the dynamic response of $2 \mathrm{D}$ servo valve is investigated by simulation. Finally, to validate the analysis, the prototype of a $2 \mathrm{D}$ valve with flow capacity of $300 \mathrm{~L} / \mathrm{min}$ (at 7Mpa) is fabricated and the pilot leakage and the actual step response are measured. The results of the experiment show that the pilot leakage is about $0.6 \mathrm{~L} / \mathrm{min}$ at $21 \mathrm{Mpa}$ and the response time for the step input is $7 \mathrm{~ms}$. It is concluded from both theoretic analysis and simulation that the 2D servo valve with a zero-overlap of pilot stage has a fairly fast dynamic response, and its pilot leakage is very small, less than $0.2 \%$.
\end{abstract}

\section{KEY WORDS}

Servo valve, Leakage, step response, two-dimensional control

\section{NOMENCLATURE}

$\alpha \quad: \quad$ Pitch angle of spiral groove

$A \quad: \quad$ End area

$A_{1}$ : Crescent overlap area between the spiral groove and hole 1

$A_{2}$ : Crescent overlap area between the spiral groove and hole 2

$B_{c}$ : Coefficient of viscous frictional force

$C_{d}: \quad$ Coefficient of the flow rate

$C_{e}$ : Modifying coefficient of flow rate

$F \quad$ : Coulumb frictional force $h_{0} \quad: \quad$ Initial overlap size of crescent area

$h_{1}$ : Height of crescent overlap area for the hole 1

$h_{2}: \quad$ Height of crescent overlap area for the hole 2

$K$ : Stiffness of the Bernoulli force

$L_{V}: \quad$ depth of left spool chamber

$m$ : Mass of spool

$p_{A}: \quad$ Pressure of main valve port $\mathrm{A}$

$p_{B}: \quad$ Pressure of main valve port $\mathrm{B}$

$p_{c}: \quad$ Pressure of the left spool chamber

$p_{s}: \quad$ Pressure of system

$q_{p}:$ pilot leakage flow 
$Q_{1} \quad$ : Flow rate entering the left spool chamber

$Q_{2}$ : Flow rate through crescent overlap area of hole 2

$Q_{l 1}$ : Flow rate entering from hole 1 through spool-sleeve clearance

$Q_{l 2}$ : Leakage through spool-sleeve from left chamber to hole 2

$r_{d}: \quad$ Radius of the hole 1 (2)

$R \quad: \quad$ Radius of spool land

$t \quad: \quad$ Time

$x_{v}: \quad$ Displacement of the spool

$\mu \quad$ : Dynamic viscosity

$\theta \quad: \quad$ Rotary angle of spool

$\rho$ : Density of oil

$\gamma \quad: \quad$ Angle of the small width $d l$

$\delta \quad: \quad$ Clearance between spool and sleeve

\section{INTRODUCTION}

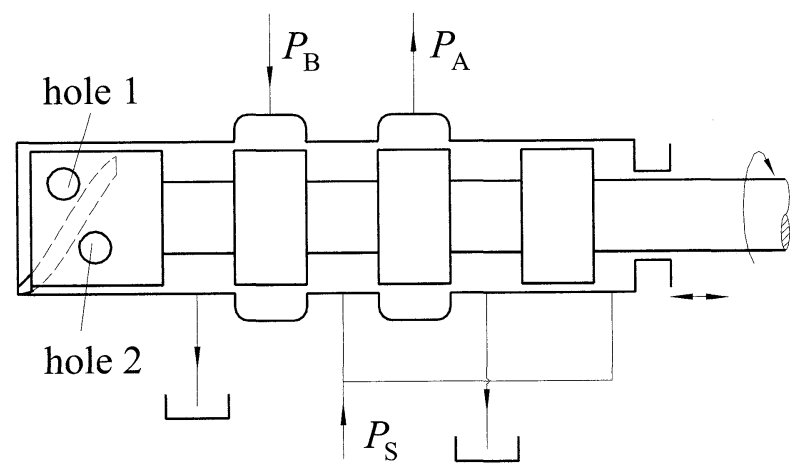

Figure $12 \mathrm{D}$ servo valve with a zero-overlap of pilot stage

The electrohydraulic servo valve plays a key role in the electrohydraulic servo systems and usually determines the performance of the whole systems to a great extent. The well-known nozzle-flapper servo valve has a fairly fast dynamic response due to the small inertia of its armature-flapper-wire assembly, but it is very sensitive to the contamination of oil media. Moreover, there is always a constant leakage flowing through the gaps between the nozzles and flapper, which results in a substantial power loss in the system, especially when the system is running at high pressure, for the value of the power loss is proportional to the square of the system pressure. As for the jet pipe servo valve, the tolerance to contamination has somewhat been improved, but at the price of even greater pilot leakage and power loss. The $2 \mathrm{D}$ servo valve (shown in Figure 1) is designed with two-dimensional structure of a single spool and its dynamic performance is chiefly dominated by the hydraulic servo mechanism for the rotary-to-linear motion conversion. Because the natural frequency of the hydraulic servo mechanism is extremely high, up to about $10^{4}$ to $10^{5} \mathrm{~Hz}$, the $2 \mathrm{D}$ servo valve potentially possesses high performances both dynamic and static. In previous studies, its pilot stage is designed with a certain hatch to increase stability. But this results in the leakage of the pilot stage and power loss. Therefore, a $2 \mathrm{D}$ valve designed with zero-overlap, hence with tiny pilot leakage, is proposed in this paper.

\section{ANALYSIS OF PILOT LEAKAGE FLOW}

2D servo valve with a zero-overlap of pilot stage does not have hatch, the pilot leakage is mainly generated via the clearance between the valve spool and the vale sleeve. Under static conditions, the flow enters the left valve chamber through the clearance via hole 1 (high pressure hole) and then discharges through the clearance via hole 2 (low pressure hole) to tank, so the pilot leakage occurs. As the clearance is very small, the leakage flow is considered to be laminar flow and can be considered the same as that as exists in the clearance formed by two parallel plates. Therefore, based on the model of tiny volume with small width through the clearance between two parallel plates, the leakage flow of $2 \mathrm{D}$ servo valve with a zero-overlap of pilot stage can be calculated theoretically.

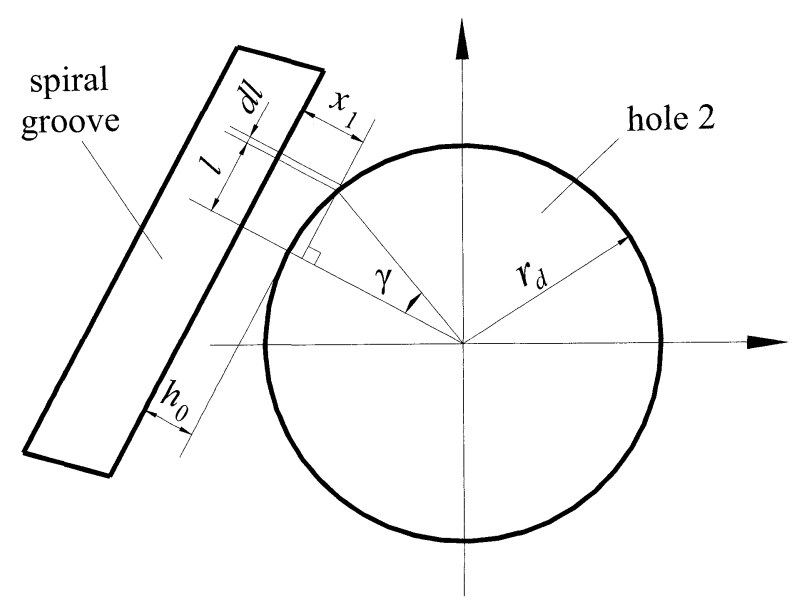

Figure 2 Pilot leakage flow

With reference to Figure 2, the flow of a tiny volume with small width $d l$ through the clearance between two parallel plates can be described as follow

$$
d q_{p}=\frac{\delta^{3} \Delta p d l}{12 C_{e} \mu x_{1}}
$$

Where $d q_{p}$ is the flow of a tiny volume with width 
$d l$ through the clearance between two parallel plates; $\Delta p$ is the pressure difference between the hole and the spiral groove.

For the high pressure hole, $\Delta p=p_{s}-p_{c}$; for the low pressure hole, $\Delta p=p_{c} ; x_{1}$ is the distance from the spiral groove to the hole.

Based on the geometry shown in Figure 2, the following equations can be obtained

$$
l=r_{d} \sin \gamma
$$

$$
x_{1}=h_{0}+r_{d}(1-\cos \gamma)
$$

Applying the derivative to Eq. (2), the following equation can be derived

$$
d l=r_{d} \cos \gamma d \gamma
$$

Substituting Eq. (3) and Eq. (4) into Eq. (1), the pilot leakage flow $q_{p}$ is obtained

$$
q_{p}=-\frac{\delta^{3} \Delta p \pi}{12 C_{e} \mu}+\frac{\delta^{3} \Delta p}{3 C_{e} \mu} \frac{h_{0}+r_{d}}{\sqrt{h_{0}\left(h_{0}+2 r_{d}\right)}} \operatorname{arctg} \sqrt{\frac{h_{0}+2 r_{d}}{h_{0}}}
$$

In terms of Eq. (5), the pilot leakage can be calculated at different system pressure, shown in Table 1.

Table 1 Theoretic value of leakage rate

\begin{tabular}{|c|c|c|c|c|}
\hline $\begin{array}{c}\text { Pressure } \\
{[\mathrm{MPa}]}\end{array}$ & 5 & 10 & 15 & 21 \\
\hline $\begin{array}{c}\text { Leakage rate } \\
{[\mathrm{L} / \mathrm{min}]}\end{array}$ & 0.1088 & 0.2175 & 0.3263 & 0.4568 \\
\hline
\end{tabular}

\section{ANALYSIS OF DYNAMIC CHARACTERISTIC}

To analyze the dynamic response of the $2 \mathrm{D}$ servo valve with zero-overlap pilot stage, its mathematical model is established. It can be described through flow rate continuity equation and spool motion equation.

\section{Flow rate continuity equation}

In the dynamic process, the flow rate entering the left valve chamber is mainly composed of two parts. One part is the flow rate entering the left chamber through the crescent overlap area of the hole 1 , and other part is the flow rate entering from hole 1 through the clearance between the spool and the sleeve. Correspondingly, the flow rate discharging the left chamber is also composed of two parts: the flow rate through the crescent overlap area of the hole 2 and the flow rate from the spiral groove to tank through the spool-sleeve clearance. Therefore, according to the flow rate continuity, the following equation is obtained

$$
Q_{1}+Q_{l 1}-Q_{2}-Q_{l 2}=A \frac{d x_{v}}{d t}+\frac{A\left(L_{V}+x_{v}\right)}{\beta_{e}} \frac{d p_{c}}{d t}
$$

The flow rate $Q_{1}$ can be calculated by the following equation

$$
Q_{1}=C_{d} A_{1} \sqrt{\frac{2\left(p_{s}-p_{c}\right)}{\rho}}
$$

$A_{1}$ is the crescent overlap area between the spiral groove and the hole 1 . It is dependent upon their relative geometric position. With reference to Figure $2, A_{1}$ can be expressed as:

$$
A_{1}= \begin{cases}0 & \left(h_{1}<0\right) \\ h_{1} \sqrt{2 r_{d} h_{1}-h_{1}{ }^{2}}+r_{d}^{2} \arcsin \frac{\sqrt{2 r_{d} h_{1}-h_{1}^{2}}}{r_{d}}-r_{d} \sqrt{2 r_{d} h_{1}-h_{1}^{2}} & \left(0<h_{1} \leq r_{d}\right) \\ \pi r_{d}^{2}+h_{1} \sqrt{2 r_{d} h_{1}-h_{1}^{2}}-r_{d}^{2} \arcsin \frac{\sqrt{2 r_{d} h_{1}-h_{2}{ }^{2}}}{r_{d}}-r_{d} \sqrt{2 r_{d} h_{1}-h_{1}{ }^{2}} & \left(r_{d}<h_{1} \leq 2 r_{d}\right) \\ \pi r_{d}^{2} & \left(h_{1} \geq 2 r_{d}\right)\end{cases}
$$

Where $h_{1}$ is the height of the crescent overlap area for the hole 1 . 
With reference to Figure 2, $h_{1}$ can be described as follow

$$
\begin{gathered}
Q_{2}=C_{d} A_{2} \sqrt{\frac{2 p_{c}}{\rho}} \\
h_{2}=-R \theta \sin \alpha+x_{v} \cos \alpha-h_{0}
\end{gathered}
$$

Similarly, $Q_{2} 、 h_{2}$ and $A_{2}$ are respectively described as follow

$$
A_{2}= \begin{cases}0 & \left(h_{2}<0\right) \\ h_{2} \sqrt{2 r_{d} h_{2}-h_{2}^{2}}+r_{d}^{2} \arcsin \frac{\sqrt{2 r_{d} h_{2}-h_{2}^{2}}}{r_{d}}-r_{d} \sqrt{2 r_{d} h_{2}-h_{2}^{2}} & \left(0<h_{2} \leq r_{d}\right) \\ \pi r_{d}^{2}+h_{2} \sqrt{2 r_{d} h_{2}-h_{2}^{2}}-r_{d}^{2} \arcsin \frac{\sqrt{2 r_{d} h_{2}-h_{2}^{2}}}{r_{d}}-r_{d} \sqrt{2 r_{d} h_{2}-h_{2}^{2}} & \left(r_{d}<h_{2} \leq 2 r_{d}\right) \\ \pi r_{d}^{2} & \left(h_{2} \geq 2 r_{d}\right)\end{cases}
$$

\section{Spool motion equation}

The equation of motion for the spool is given by:

$$
p_{c} A-\frac{1}{2} p_{s} A=m \frac{d^{2} x_{v}}{d t^{2}}+B_{e} \frac{d x_{v}}{d t}+K x_{v}+F
$$

Equation (6) (13) form the basis of the mathematical model of the $2 \mathrm{D}$ serve valve with zero-overlap pilot stage. These equations are nonlinear and solved using numerical computation method. The simulation pattern is shown in Figure 3. From Figure 3, the rising time is about $6 \mathrm{~ms}$.

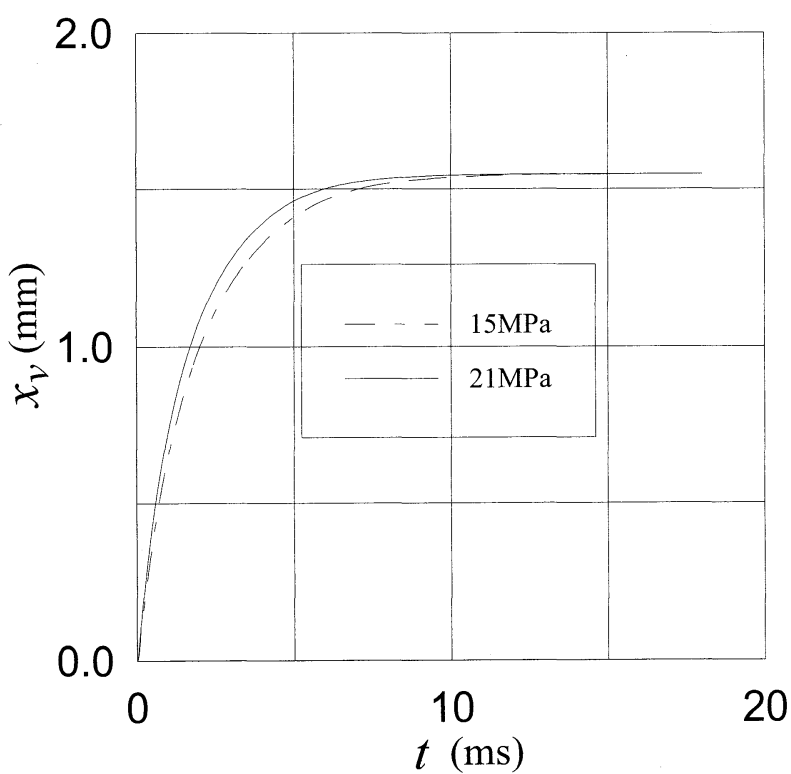

Figure 3 Simulation pattern

\section{EXPERIMENT}

To validate the analysis, the actual test is carried out on an experimental set-up.

\section{Measurement of leakage rate from the pilot}

Figure 4 is the experimental set-up of leakage rate of the pilot. The leakage rate was measured using a calibrated glass and a stopwatch. To prevent leakage from the valve port via the spool-sleeve clearance of the central spool land from entering the calibrated glass, port $P_{\mathrm{B}}$ is connected to tank and port $P_{\mathrm{A}}$ blocked off. The measured data is listed in Table 2. It should be noted that the measured leakage flow rate included the leakage through the spool-sleeve clearances. From Table 2, it can be clearly seen that the pilot leakage is $0.6 \mathrm{~L} / \mathrm{min}$ at $21 \mathrm{MPa}$. The data agrees well to the theoretical calculation result and the leakage flow of the pilot is small.

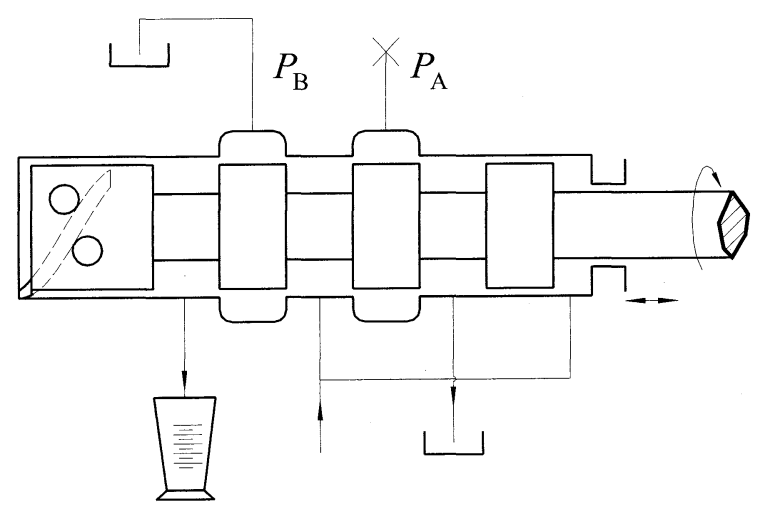

Figure 4 Experimental set-up of leakage rate of the pilot 
Table 2 Measurement of leakage rate

\begin{tabular}{|c|c|c|c|c|}
\hline $\begin{array}{c}\text { Pressure } \\
{[\mathrm{MPa}]}\end{array}$ & 5 & 10 & 15 & 21 \\
\hline $\begin{array}{c}\text { Leakage rate } \\
{[\mathrm{L} / \mathrm{min}]}\end{array}$ & 0.174 & 0.316 & 0.435 & 0.6 \\
\hline
\end{tabular}

\section{Experiment of step response}

Figure 5 is the experimental set-up of the step response. In Figure 5, One end of a steel rob was connected with the spool, and the other end was tied with a steel wire. By pulling the steel wire quickly, the step of spool's rotation was created and the spool also made a linear motion correspondingly in respect to its rotation. The linear motion of the spool was measured with a laser displacement sensor and recorded in an oscilloscope. The measured step response is shown in Figure 6. From Figure 6 , it can be clearly seen that the linear motion of the spool in response to its rotation is very fast, and the responding time is about $7 \mathrm{~ms}$ at $21 \mathrm{MPa}$. This result also proves the correctness of the theoretical analysis.

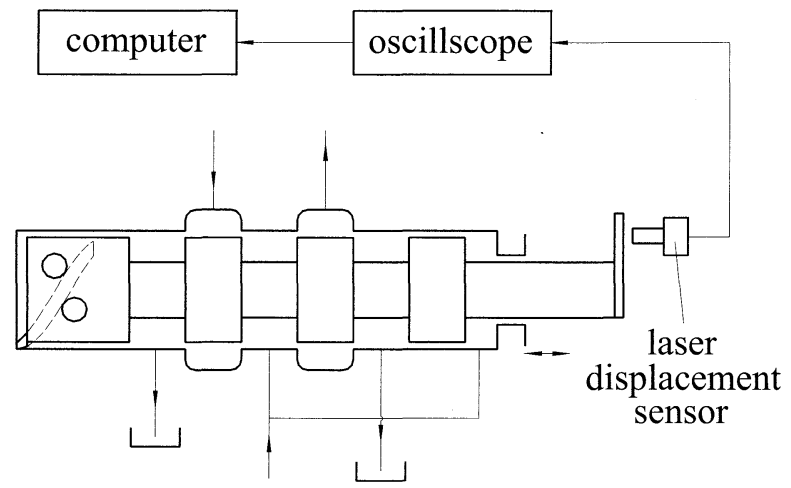

Figure 5 Experimental set-up of step response

\section{CONCLUSION}

$2 \mathrm{D}$ servo valve with zero-overlap is composed of a pilot control valve designed with both rotary and linear motions of a single spool. Because of the extremely large value of the hydraulic natural frequency, the $2 \mathrm{D}$ servo valve potentially possesses high performances both dynamic and static. Either simulation analysis of 2D servo valve with zero-overlap or experiment makes it clear that it has fast dynamic response. The step response time is about $7 \mathrm{~ms}$. It is also shown its pilot leakage is very small.

\section{ACKNOWLEDGEMENTS}

The authors would like to offer their gratitude to The National Foundation of Natural Sciences (No. 50675204), the Foundation of Natural Sciences of Zhejiang Province (No.Y106165) and the Foundation of the MOE Key Laboratory of Mechanical Manufacture and Automation who sponsored the project. Gratitude is also extended to the Watch Manufacturing Factory of Hangzhou who helped machine the testing elements.

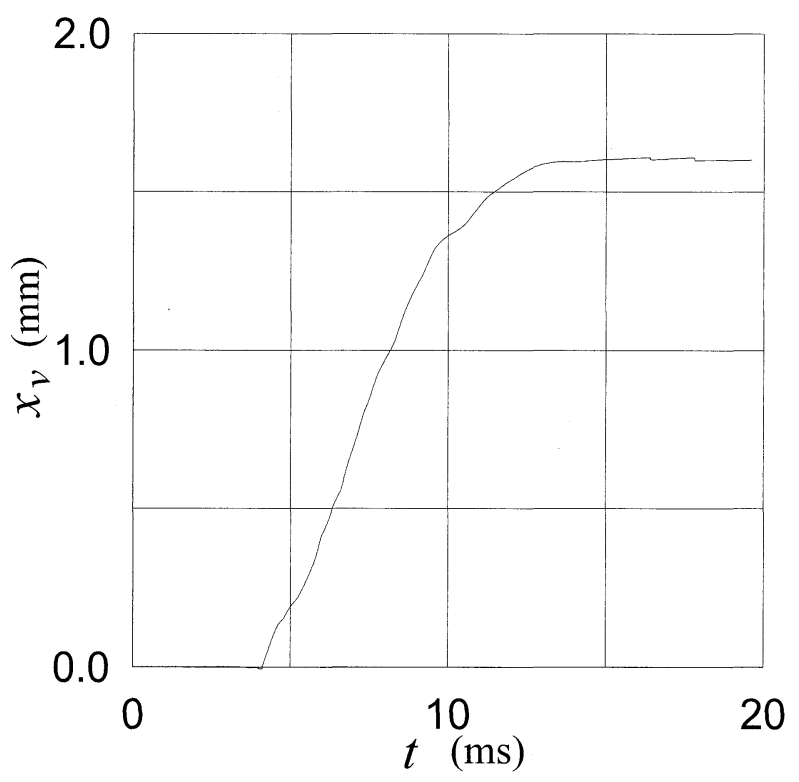

(a) $15 \mathrm{MPa}$

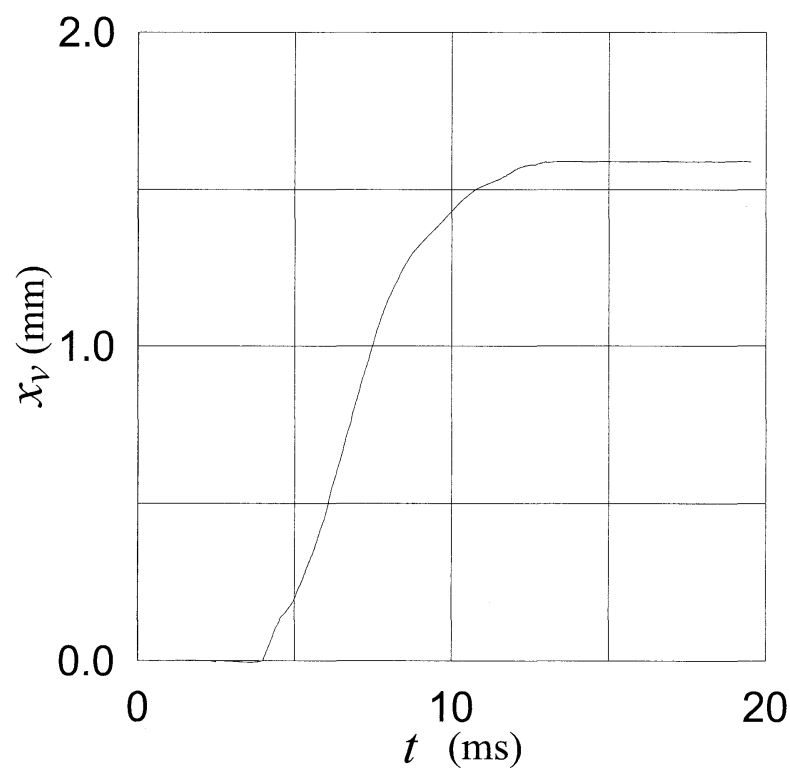

(b) $21 \mathrm{MPa}$

Figure 6 Measured step response 


\section{REFERENCES}

1. J. Ruan, R. Burton and P. Ukrainetz, An Investigation Into the Characteristics of a Two Dimensional "2D" Flow Control Valve, Journal of Dynamic Systems, Measurement and Control, Transactions of ASME, Vol 124, March 2002,pp.214 220.

2. Maskrey, R. H.,Thayer, W. J., Brief History of Electrohydraulic servomechanisms, Journal of Dynamic Systems, Measurement and Control, June 1978.

3. Merritt, H. E., Hydraulic Control Systems, John Wiley \& Sons, New York, 1967, pp.67 86
4. Ruan Jian, Electro-hydraulic (pneumatic) Direct Digital Control. Press of Zhejiang University, Hanzhou, 2000, pp.45 48.

5. Li H. R., Electro-hydraulic Control Systems, National Defense Press, 1981.

6. Ruan J., Ukrainetz, P. R. and Burton ,R.,Frequency Domain Modeling and Identification of 2D Digital Servo Valve, International Journal of Fluid Power,2001,1,pp.49 58.

7. Wang Y., et al., Mathematics Handbook, Mass Education Press, 1977,pp.37 